Revista de la red interuniversitaria de estudios sobre las literaturas rioplatenses contemporáneas en Francia

$8 \mid 2013$

Argentina y Uruguay: lecturas del país vecino en la literatura rioplatense contemporánea (siglos XX y XXI)

\title{
Las delicias de la jaula
}

\section{Marcelo Damiani}

\section{OpenEdition}

\section{Journals}

Edición electrónica

URL: http://journals.openedition.org/lirico/1025

DOI: 10.4000/lirico.1025

ISSN: 2262-8339

Editor

Réseau interuniversitaire d'étude des littératures contemporaines du Río de la Plata

Referencia electrónica

Marcelo Damiani, « Las delicias de la jaula », Cuadernos LIRICO [En línea], 8 | 2013, Publicado el 01 enero 2013, consultado el 22 septiembre 2020. URL : http://journals.openedition.org/lirico/1025 ; DOI : https://doi.org/10.4000/lirico.1025

Este documento fue generado automáticamente el 22 septiembre 2020

\section{(c) (i) () $\Theta$}

Cuadernos LIRICO está distribuido bajo una Licencia Creative Commons Atribución-NoComercialSinDerivar 4.0 Internacional 


\section{Las delicias de la jaula}

Marcelo Damiani

\section{REFERENCIA}

Héctor Libertella, A la santidad del jugador de juegos de azar, Buenos Aires, Mansalva, 2011, $96 \mathrm{p}$. 
1 Héctor Libertella (1945-2006) empezó su carrera ayudado por el impacto que genera el haber ganado dos importantes concursos literarios. En 1968, el Premio Paidós de Novela con El camino de los hiperbóreos, y en 1971 el de Monte Ávila, con Aventuras de los miticistas. Poco después, el joven escritor formaba parte de los colaboradores de la revista Literal, que, según sus propias palabras, "traía una novedad perversa : el lento destilado del psicoanálisis en la literatura". ${ }^{1} \mathrm{Su}$ prestigio se consolidó luego con la publicación del ensayo Nueva escritura en Latinoamérica (1977), donde proponía un uso ambiguo de la palabra vanguardia; esta - decía- “empieza a corresponderse no con lo que está más adelante, sino con lo que está más íntimo". ${ }^{2}$ A partir de ese
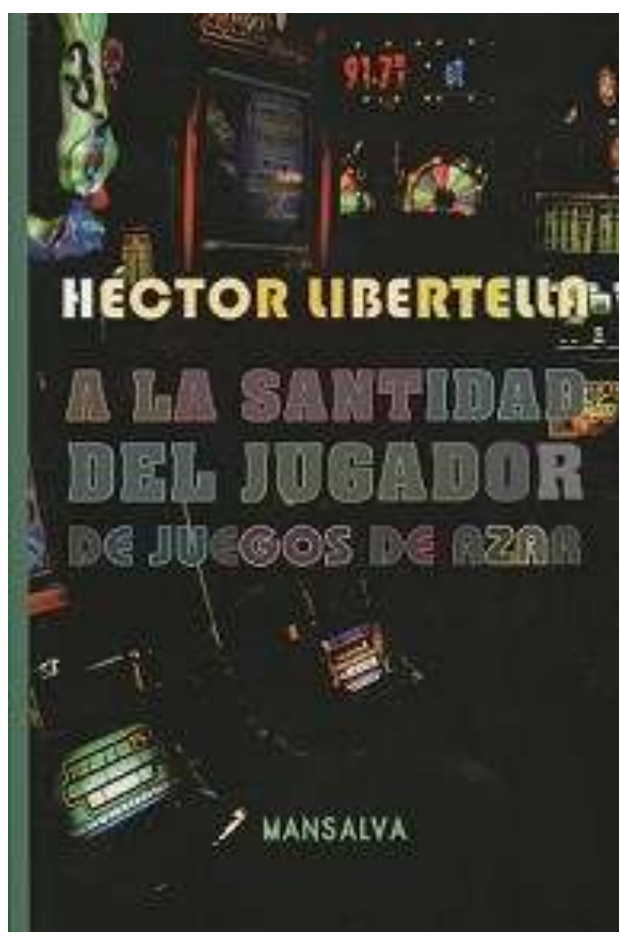
momento, Libertella se convirtió en una suerte de código o clave secreta del sentido y el afán literario argentino. Con la publicación de El árbol de Saussure (2000), sus textos terminan de encontrar un espacio que siempre parecen haber estado buscando, un lugar a medio camino entre la ficción huidiza y la reflexión teórica. Fue también por esa época cuando comenzó a poner en práctica un método obsesivo: se dedicó a reescribir todo lo que había escrito en el siglo XX. De esta suerte de "remix de sí mismo" (como lo llama Rafael Cippolini) surgen textos como La librería Argentina (2003), La arquitectura del fantasma. Una autobiografía (2006), Zettel (2009) y, por último, A la santidad del jugador de juegos de azar, la arriesgada apuesta lúdico-aleatoria publicada por la editorial Mansalva a fines de 2011.

2 Construido, a primera vista, como una colección de biografías monstruosas, un poco a la manera de las vidas infames narradas por Borges, este libro prolonga en realidad la línea iniciada en El árbol de Saussure; es decir: una deriva textual cada vez más pronunciada hacia lo informe, lo múltiple y lo inacabado, siguiendo un patrón circunscripto a la lógica del deseo. En este sentido, parecería aludir a un cierto lugar que la ficción argentina, entregada en gran parte a eso que César Aira ha llamado "un realismo de barrio elegante, de Palermo Soho", ha ido perdiendo poco a poco en las últimas décadas. En cambio, la escritura lúdica y digresiva de Libertella, de clara raigambre macedoniana, cuestiona todo lo que encuentra a su paso, empezando por el lenguaje mismo. Esta propuesta se lleva adelante por medio de una doble táctica de seducción irónica y de postergación sempiterna del sentido final ; y hasta podríamos decir que, respecto del sentido, el escritor se comporta como ese perverso tipo de jugador que nunca busca ganar.

3 A la par de esa apuesta por la reescritura compulsiva que inició en el nuevo siglo, durante sus últimos años Libertella se dedicó a distribuir, entre colegas y amigos, sus manuscritos inéditos en versiones ligeramente distintas, con la intención de disolver la idea de "Obras Completas". En A la santidad del jugador de juegos de azar, esa necesidad de 
disolución estalla en el capítulo fantasma del volumen : "Góngora. Nada de lo humano", solo presente en el índice (sin número de página) y en el prólogo ("Góngora será el destino..."). Ese texto ausente funciona como una metáfora de la des-obra y, a la vez, como una suerte de agujero negro que por momentos amenaza con absorber todo el libro. $^{3}$

4 En este sentido, el segundo texto, "Desimone. Fobia y placer", es emblemático. Allí, con alusiones a cierto líder político argentino (probablemente Vandor), Libertella construye en pocas páginas la historia del lobo Desimone, "jefe de gobierno, dueño de la política italiana" (17), que ha elegido vivir encerrado en una celda. Para Desimone, la "voluptuosidad del poder se resume en las delicias de esa jaula. Desde allí, él dirige la reconstrucción del país. Y mientras cumple un destino público opta por sustraer su cuerpo" (17). El doble gesto que consiste en elegir la propia reclusión y sustraer el cuerpo al goce del otro, pero sin dejar de cumplir al mismo tiempo "un destino público", podríamos conectarlo, en el sistema libertelliano, con la "muy vieja familia" de las escrituras herméticas, cerradas y ocluidas como la poesía del trobar clus, pero no por ello menos presentes y activas en las tribus literarias latinoamericanas. En Las sagradas escrituras (1993), Libertella había esbozado un retrato de esas prácticas, que iban desde "el macizo Corpus Hermeticum [...] al hipergongorismo, del grafismo al concretismo, del grotesco a los idiolectos, del pastiche Siglo de Oro español, al filosurrealismo y, por último, a la ficción teórica". ${ }^{4}$ También imaginaba que ese retrato tenía la forma de "redes-rejas". Hace veinte años, estas eran las delicias de la jaula libertelliana. ¿Cuáles serían hoy? ¿Es posible reconocer en la literatura contemporánea los rasgos de la vieja familia hermética? ¿O hablamos de un linaje ya extinguido?

5 Pero volvamos mejor a Desimone. Su acto fóbico es a la vez íntimo y fastuoso, reconcentrado y monumental, pues "el Lobo" se propone, desde las sombras, reconstruir todo un país. Esta particular fusión de habitación hermética donde se sustrae un cuerpo con palacio de gobierno, de cárcel con monumento, evoca eso que los psicoanalistas $-\mathrm{y}$ recordemos las lecturas teóricas de los jóvenes que publicaban Literal - han llamado "histeria". Freud afirma: "Nuestros enfermos histéricos padecen de reminiscencias. Sus síntomas son restos y símbolos mnemónicos de determinadas experiencias (traumáticas)". ${ }^{5} \mathrm{Y}$ a continuación agrega: "Una comparación con los símbolos conmemorativos que hallamos en otros ámbitos quizá nos conduzca a una comprensión más profunda de esta simbólica. También son símbolos mnemónicos las estelas y monumentos con que adornamos nuestras grandes ciudades". ${ }^{6}$ Más tarde, Jacques Lacan dará a esos monumentos un matiz de hermetismo al hablar, en un pasaje célebre de su "Informe de Roma", de los "jeroglíficos de la histeria".7 La literatura de Libertella participa de de esos signos histéricos, donde algo íntimo se proyecta, de modo enigmático, en lo monumental y en lo público (es decir, en lo publicado). Una palabra valija inventada por Hélène Cixous dice esto brevemente : l'hystérature. ${ }^{8}$

6 Es posible conjeturar que a esa práctica histérica alude también una pieza como "James Cook. Ojo : jeroglífico". Del texto mismo al índice final del libro, este título ha sufrido un cambio: en la página 41, el nombre del protagonista aparece directamente acompañado por una sucesión de signos incomprensibles, donde diferentes alfabetos y marcas tipográficas se mezclan del modo más promiscuo ; en el índice, la palabra "ojo" se lee como una advertencia irónica frente al horror que suele provocar el sinsentido. Es que, como nota Maximiliano Crespi, el jeroglífico literario "amenaza con suspender el totalitarismo del lenguaje naturalizado en que se sella el maridaje de servilismo y 
poder"9. Frente a su existencia perturbadora, el régimen de verdad solo atina a enviarlo al reducto de lo artístico (o lo patológico), para salvaguardar el imperativo de la comunicación. El resto, parece decir, es literatura (y silencio). Así, el jeroglífico puede leerse como una fulguración secreta, una suerte de sujeto (sentido) que se encierra sobre sí mismo y desde su encierro, paradójicamente, cumple su "destino público". De este modo, permite repensar la literatura como manifestación de lo residual, de lo incierto, de lo desconocido, de lo impensable y, sobre todo, de lo imposible; como una forma privilegiada de resistencia frente a la vacuidad infinita de los discursos que nos gobiernan.

7 Freud, en el texto citado más arriba, nos dice del histérico que padece reminiscencias. La palabra padecer remite en latín al verbo pati, y este a un sustantivo griego con el que suele jugar Libertella : pathos. Esta palabra designa, en su sentido más general, lo que le pasa a alguien o a algo, lo que alguien o algo experimenta o sufre (el sentido que tiene en retórica deriva de esta acepción). Los diccionarios explican también que el verbo correspondiente -el verbo páscho- debe ser comprendido en contraste con poiéo ("hacer"). Antes que un poeta o un "hacedor" de la estirpe borgeana, para Libertella el escritor es más bien un patógrafo, alguien que sabiéndose atrapado por los signos que emite, escribe lo que padece. Entre los patógrafos y los hacedores habría relaciones tan complejas como las que se tejen entre Borges y Macedonio : "El diálogo entre estos dos modos de escribir se resolverá [en Borges] con una fórmula táctica, que fue la de su pervivencia y que sigue funcionando, con alternativa eficacia, en el cuerpo social y político de la Argentina toda $:$ SALUD = REPRESIÓN - ¿el canon reprime ?". ${ }^{10}$

Podríamos decir que ese mismo diálogo, pero resuelto de un modo muy distinto, continúa en A la santidad del jugador de juegos de azar. Pues si las vidas extravagantes que este libro presenta no dejan de aludir a Historia universal de la infamia, parecen, en cambio, haber sido transcriptas por un amanuense macedoniano, adicto a los jeroglíficos y a las digresiones menos domesticadas de la patografía argentina.

\section{NOTAS}

1. H. Libertella (comp.), Literal 1973-1977, Buenos Aires, Santiago Arcos, 2002, p. 5.

2. Nueva escritura en Latinoamérica, Buenos Aires, El Andariego, 2008, p. 34 (la bastardilla es del autor).

3. Para una definición de la des-obra, ver Antelo, Raúl, "La des-obra como ready-made", en Cuadernos LIRICO $\mathrm{N}^{\circ} 4$ (2008). Antelo afirma : "Roland Barthes, ese disciplinado alumno de Lacan, nos propuso el pasaje de la obra al texto, o sea, el pasaje de lo orgánico a lo maquínico, de lo estésico a lo anestésico, de lo individual a lo anonyme, en suma, de la obra al dés-œuvrement, abriéndonos así la perspectiva inoperante del texte. Diferenciado, e incluso diferido, con relación a la obra, podemos traducir el texte como des-obra. La des-obra nos exige una ética de lectura que va más allá de la interpretación" (p. 17). Y, un poco después: "Son intervenciones que marcan una clara caída de la idea misma de vanguardia o incluso de la definición de obra, en el sentido en que subrayan el agotamiento de la autonomía formal-ideal. Allí se encajan artistas como Osvaldo Lamborghini o Héctor Libertella" (p. 25). 
4. Las sagradas escrituras, Buenos Aires, Sudamericana, 1993, p.67. La mención del hipergongorismo nos permite comparar la figura del jefe de gobierno Desimone con la del Dr. Francia, quien, en la novela de Roa, sustrae su cuerpo público de dictador en el corpus hermeticum de una sintaxis : "...por qué Roa Bastos incrusta en Yo el Supremo un hipergongorismo de esta especie : 'Clavada la Revolución en mi cabeza la pica guíñame su ojo cómplice desde la Plaza'. Perdido en esta sintaxis, ya no llego por ningún lado al dictador latinoamericano que tantos estudiaron" (H. Libertella, "Patografía, vanguardia, posmodernidad", en AA.VV, Literatura y crítica : Primer encuentro, Santa Fe, Universidad Nacional del Litoral, p. 99-104).

5. S. Freud, Gesammelte Werke Bd. VIII (1909-1913), Frankfurt/Main, S. Fischer, 1987, p. 10.

6. Ibíd.

7. "Hiéroglyphes de l'hystérie, blasons de la phobie, labyrinthes de la Zwangneurose, - charmes de l'impuissance, énigmes de l'inhibition oracles de l'angoisse, - armes parlantes du caractère, sceaux de l'auto-punition, déguisement de la perversion- tels sont les hermétismes que notre exégèse résout..." ("Fonction et champ de la parole et du langage en psychanalyse", en Écrits I, Paris, Seuil, 1999, p. 279).

8. "L’Hystérature" es el título de la conferencia que Hélène Cixous dedicó al "discurso de la histérica" en el seminario sobre los cuatro discursos de Lacan que tuvo lugar en la Universidad de París 8, el 24 de marzo de 2009.

9. M. Crespi, La conspiración de las formas. Apuntes sobre el jeroglifico literario, La Plata, UNIPE, 2011, p. 17.

10. La Librería Argentina, Córdoba, Alción Editora, 2003, p. 77.

\section{AUTORES}

\section{MARCELO DAMIANI}

Universidad Nacional de General Sarmiento, Instituto de Literatura Iberoamericana, Universidad de Buenos Aires 